\title{
O Amor entre Jovens em Tempos de Ficar: Correlatos Existenciais e Demográficos
}

Love Among Youngsters In Times Of Casual Relationships: Existential And Demographic

Correlates

El Amor Entre Los Jóvenes En Tiempos De "Rollo": Correlatos Existenciales Y Demográficos

Thiago Antônio Avellar de Aquino, Valdiney Veloso Gouveia, Karizy Soany Costa

Patrício, Maria Gorete Sarmento da Silva,Jacqueline Lisete de Macedo Bezerra, Valdemir Bezerra de Souza Júnior \& Waldemar Moreira de Oliveira Neto

Universidade Federal da Paraíba

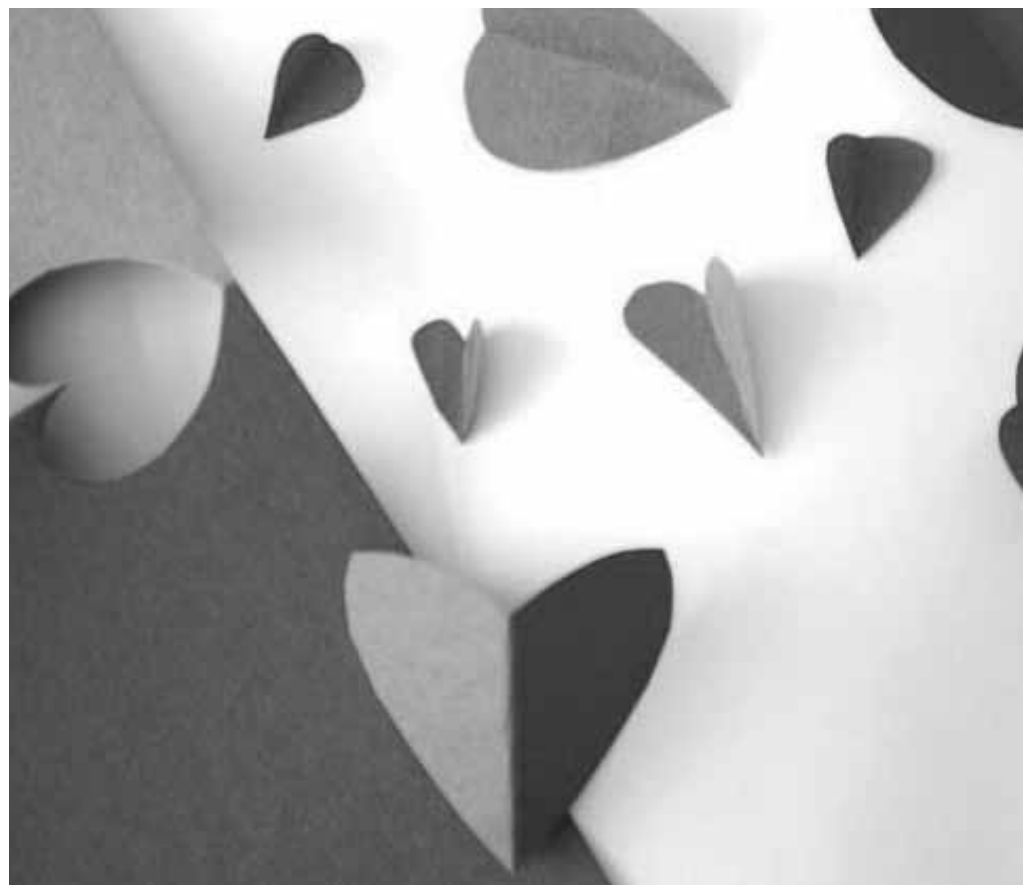


Resumo: O objetivo deste estudo foi conhecer em que medida o amor e o ficar se correlacionam e como ambos se relacionam com o sentido da vida e com o vazio existencial. Complementarmente, procurou-se conhecer evidências de validade fatorial e de consistência interna da medida de amor. Participaram 199 estudantes universitários (51\% mulheres), com idade média de 21 anos, que responderam a versão revisada do Teste Propósito de Vida e a Escala Tetrangular do Amor (ETA). Os resultados apoiaram a adequação do modelo tetrafatorial da ETA. Três de seus fatores (compromisso, paixão romântica e intimidade) se associaram positivamente à realização existencial; a intimidade o fez negativamente com o desespero, e o vazio existencial e a paixão romântica, ao vazio existencial. No caso do ficar, este se correlacionou negativamente com os fatores compromisso, intimidade e paixão romântica. Esses resultados foram discutidos à luz da logoterapia, que considera o amor uma via para obter o sentido da vida.

Palavras-chave: Logoterapia. Interação interpessoal. Amor. Afeição.

Abstract: This study aimed to know the correlation between love and staying and how both are correlated to the life meaning and existential void. In addition, it tried to know evidences of factorial validity and reliability of the measure of love. The participants were 199 undergraduate students (51\% women) with the mean age of 21 years. They answered the revised version of the Life Purpose Test and the Tetra-dimensional Love Scale $(T L S)$. Results supported the adequacy of the tetra-factorial model for the TLS. Three of its factors (commitment, intimacy, and romantic passion) were positively associated with existential realization; intimacy did negatively with despair and existential void, and romantic passion did it with the existential void. With respect to staying, it was negatively correlated with the love factors commitment, intimacy and romantic passion. The discussion of these findings was based on logotherapy, that considers love a way to get the meaning of life.

Keywords: Logotherapy. Iterpersonal interaction. Love. Affection.

Resumen: El objetivo de este estudio fue conocer en qué medida el amor y el ficar (tener relaciones esporádicas) se correlacionan entre sí, y cómo ambos se relacionan con el sentido de la vida y el vacío existencial. Complementariamente, se procuró conocer evidencias de validez factorial y consistencia interna de la medida de amor. Participaron 199 estudiantes universitarios (51\% mujeres) con edad media de 21 años. Estos respondieron la versión revisada del Test Propósito de Vida y la Escala Tetrangular del Amor (ETA). Los resultados apoyaron la adecuación del modelo tetrafactorial de la ETA. Tres de sus factores (compromiso, pasión romántica e intimidad) se asociaron positivamente con la realización existencial; la intimidad lo hizo negativamente con el desespero y el vacío existencial y la pasión romántica con el vacío existencial. En el caso del ficar (tener relaciones esporádicas), se correlacionó negativamente con los factores compromiso, intimidad y pasión romántica. Estos resultados fueron discutidos a la luz de la Logoterapia, considerando el amor como una vía para obtener el sentido de la vida.

Palabras clave: Logoterapia. Iteraccion interpersonal. Amor. Afeccion.

“Não se conhece senão o que se ama, e o conhecimento será tanto mais compreensível e profundo quanto mais fortes e vivos forem o amor e a paixão" (Goethe).

O amor é um tema cantado entre os poetas e filósofos desde a Antiguidade até os tempos atuais, e constitui verdadeira fonte de inspiração para o ser humano. Inicialmente, o ideário do amor foi considerado um requisito

A presente pesquisa contou com o apoio do CNPq por meio de bolsa Produtividade em Pesquisa concedida ao segundo autor. Os autores agradecem a essa instituição. vários filósofos na Grécia, dentre eles, Sócrates, cuja finalidade era debater as concepções sobre o amor. Em O Banquete, Aristófanes descreve o amor como o responsável pela união de duas metades separadas desde a origem do ser humano. Os gregos acreditavam que, nos primórdios dos tempos, existiam três gêneros: o masculino, o feminino e o andrógino. Tais seres especiais tinham forma esférica, com quatro mãos e quatro pés, mas apenas um cérebro. Ao tentarem atacar o Olimpo, Zeus os castiga cortando-os ao meio, assim sentiram-se fracos e numerosos, sempre à procura de seu par, e quando as duas metades se encontravam, não se largavam por medo de se perderem novamente. Essa é uma primeira referência da necessidade 
O ficar, para alguns, é a possibilidade de encontrar alguém para um futuro namoro, mas, para outros, pode ser apenas a possibilidade de estar com maior número de parceiros bem como uma busca de satisfação momentânea (Caramaschi, 2007). de o ser humano buscar complemento no outro, entendendo-se que essa união apenas ocorreria por intermédio da força do amor (Platão, 1991).

No decorrer dos tempos, o amor sofreu ressignificações e revalorizações. Assim, constata-se que, na modernidade, existe um hiato entre o amor e o sexo. Nesse contexto, ganha espaço o ficar, que não é algo exclusivo dos jovens de hoje, mas um tipo de relacionamento afetivo que ocorre com a ausência de responsabilidade e de compromisso com o parceiro, visto que, em determinados instantes, não se estabelece qualquer vínculo emocional entre os ficantes. O ficar, para alguns, é a possibilidade de encontrar alguém para um futuro namoro, mas, para outros, pode ser apenas a possibilidade de estar com maior número de parceiros bem como uma busca de satisfação momentânea (Caramaschi, 2007).

Portanto, amor e ficar são elementos comuns no dia a dia, mas, qual seria mesmo a diferenciação entre ambos ou como, por outro lado, se relacionariam? Embora essa questão possa preocupar educadores, psicólogos e pais, raramente tem sido tratada de forma sistemática; são ainda escassos os estudos a respeito, principalmente os que têm em conta uma abordagem mais quantitativa, métrica. Nesse sentido, justifica-se o presente estudo. Seu objetivo principal é conhecer como o amor e o ficar se relacionam, mas também como esses sentimentos ou modos de se relacionar podem ser pautados no sentido da vida e no vazio existencial experimentado pelas pessoas. Desse modo, demanda-se compreender inicialmente o marco teórico do modelo que fundamenta o presente estudo, isto é, a análise existencial de Viktor Frankl (1905-1997), e, posteriormente, os aspectos do amor e do ficar.

\section{Análise existencial de Viktor Frankl}

A análise existencial, também conhecida como logoterapia, compreende um sistema teórico e prático dentro da Psicologia criado pelo psiquiatra e neurologista vienense Viktor Frankl (1905-1997). É uma linha existencialhumanista que busca superar o psicologismo reducionista que, por vezes, está no discurso de psicólogos. É conhecida ainda como a terceira escola vienense de psicoterapia, sendo a psicanálise freudiana a primeira e a psicologia individual, de Adler (1931/1998), a segunda. Freud descobriu no homem a vontade de prazer, Adler, a vontade de poder, e Frankl contemplou a sua vontade de sentido (Lukas, 1989).

O termo logos, do grego, significa sentido. Desse modo, a logoterapia concentra-se no sentido da existência humana e na busca do indivíduo por esse sentido, o que lhe causa uma dose saudável de tensão na qual ele se encontra entre dois polos (Frankl, 1994): um que indica o que a pessoa é, suas realizações (o ser) e, no outro, o sentido a ser cumprido (o dever ser). Esse autor percebe o homem como um ser que deseja encontrar sentido para a vida, isto é, que está destinado a descobrir o sentido de sua vida, e que pode adoecer psiquicamente se for frustrado nessa busca. A frustração dessa necessidade é um sintoma do tempo presente; o sofrimento e a falta de sentido configuram o vazio existencial que muitos experimentam. Dependendo do grau de vazio existencial, experimentam-se sintomas diversos, como depressão, irritabilidade e consumo de drogas.

A logoterapia, ao contrário da Psicologia humanista, não reconhece a autorrealização como meta última da existência humana, mas contrapõe a ela a autotranscedência do homem, que indica que o ser humano deve estar voltado para algo ou para alguém que não seja ele mesmo; dessa forma, considera o homem um ser agente, que tem o poder 
de agir, evocando a liberdade da vontade de sentido. O conceito de homem e de mundo, segundo a logoterapia, está apoiado em três aspectos principais (Lukas, 1989):

1) Liberdade da vontade. É dada ao homem potencialmente. Entende-se que o homem não está livre de condições, mas é livre para tomar qualquer posição que lhe seja mais condizente mediante as situações que o cercam, isto é, o ser humano é portador de uma liberdade condicionada;

2) Vontade de sentido. É concebida como a motivação primária do ser humano, uma capacidade própria do homem que surge a partir da tomada de consciência da finitude humana, e

3) Sentido da vida. O ser humano precisa buscar um sentido, um para quê viver, o qual deve ser um fim em si mesmo. A felicidade é a consequência da realização desse sentido que está no mundo, que é constituído de valores e de sentidos. Os valores podem ser criativos, que compõem tudo o que se cria e o que se deixa no mundo, vivenciais, que são as experiências de convívio com outras pessoas, e atitudinais, que ocorrem no sofrimento inevitável e fazem com que o indivíduo se modifique interiormente.

Nessa perspectiva teórica, a imagem do homem é formada a partir da ontologia dimensional, que enfatiza a ideia de que ele é um ser tridimensional: biológico (somático), psíquico e noético (espiritual). A dimensão somática refere-se a todos os fenômenos corporais, incluindo a estrutura fisiológica; a dimensão psíquica faz referência às condições psíquicas do homem, suas disposições, sensações, impulsos, instintos, esperanças, desejos, padrões de comportamento adquiridos e costumes sociais, e, finalmente, a dimensão noética seria aquela especificamente humana, isto é, a que o diferencia dos animais, e é nessa dimensão que se encontram as decisões pessoais de vontade, intencionalidade, pensamento criativo, senso ético e compreensão dos valores. As três dimensões são indissociáveis; o espiritual no homem compõe-se com o somático e o psíquico, sendo o homem uma unidade (Lukas, 1989).

O fenômeno do amor, segundo Frankl (1994), faz parte daquela meta mais elevada da existência humana, visto que só pode ser adquirida quando voltada para fora de si mesma, quando transcende o seu interior. O amor, em princípio, está intimamente relacionado com o sentido da vida, visto que somente por meio dele é possível apreender um outro ser humano no seu íntimo, naquilo que há de único e irrepetível (Fizzotti, 1998). Portanto, o amor é descrito como um processo primário, um fenômeno autêntico, não um epifenômeno, o que difere da visão freudiana, que o considera secundário, resultado da sublimação do impulso sexual (Lukas, 1992).

Uma frustração da vontade de sentido pode levar o indivíduo a um vazio existencial, e pode expressar-se por uma vontade de poder (busca incessante por dinheiro) ou vontade de prazer (busca pelo sexo como finalidade). Esta última poderia se refletir em um relacionamento de curta duração, que não chegaria a realizar plenamente o ser humano, pois desumaniza-o na medida em que torna o outro um objeto. Talvez isso se assemelhe à configuração do ficar, relação casual e esporádica, que visa ao prazer. Não obstante, essas são apenas conjecturas, haja vista que não se encontrou qualquer estudo empírico a respeito.

\section{O amor na análise e Frankl}

O amor, em Viktor Frankl, tinha uma conotação bem particular. Enquanto Freud (1929/1974) o concebia como um subproduto da sexualidade, com uma visão mais biologicista, e May (1992) o definia como uma força motivadora, Frankl (1994) o contemplava como um encontro 
ou um ato-coexistencial entre um eu e um $t u$, sendo esse um elemento essencial ou uma das vias para a realização do sentido na vida. $\mathrm{O}$ amor, portanto, não poderia ser concebido como um mero epifenômeno, pois, segundo a visão desse autor, constitui um ato específico de ser humano. Nesse marco, ele distingue a sexualidade, a eroticidade e o amor, estabelecendo entre tais modalidades uma hierarquia crescente em termos de humanização (Frankl, 1989).

A atitude sexual diante de um tu está em correspondência com a dimensão corporal, em que o impulso sexual se fixa em um determinado tipo físico. Na atitude erótica, que corresponde à dimensão psíquica, encontra-se o fenômeno da paixão, e, nele, a excitação não emana apenas do físico, mas, principalmente, do anímico, sentindo-se o indivíduo atraído por um determinado tipo psíquico. Essa última atitude é considerada mais profunda que a anterior, porém a atitude de amar é ainda mais elevada (Frankl, 1989), já que atinge o cerne mais profundo do ser humano, que corresponde à dimensão noética. É nessa dimensão que o(a) companheiro(a) é percebido(a) como insubstituível, pois ele(ela) não se pauta apenas no tipo físico ou psicológico, mas, acima de tudo, na condição única e irrepetível do ser humano. O amor, nesse contexto, é compreendido como "a mais alta forma de companheirismo" (Frankl, 1989, p. 175), que está direcionado para a essência do ser humano.

Diante dessa descrição, fica evidente que Frankl (1994) propõe uma gradação do amor, que vai da camada superficial (sexualidade) à mais profunda (o amor propriamente dito). $\mathrm{O}$ amor direcionado para a dimensão corpórea proporciona o prazer, e aquele dirigido à dimensão psíquica garante a alegria, mas apenas o que caracteriza a dimensão noética é capaz de assegurar que a pessoa amada seja percebida como insubstituível, promotora de felicidade plena. Nessa perspectiva, estima- se que o estágio último de desenvolvimento sexual psíquico normal se daria quando o desejo sexual estivesse dirigido exclusivamente ao ser amado; nesse amor profundo, a relação sexual torna-se um meio, e não um fim em si mesmo (Frankl, 1989). Deste modo, a dimensão superior abarca as inferiores, com o amor na dimensão noética integrando as dimensões erótica e sexual. Frankl (1994), portanto, concebe a relação sexual como uma expressão, e não como um fim; quando o sexo for intencionado para a obtenção de prazer puro, o ser humano se depara com o desprazer ou o vazio existencial. Isso pode ser algo que se apreciaria em relações momentâneas, como as vivenciadas em práticas de ficar.

\section{O amor do ponto de vista psicológico}

Tratou-se até aqui diretamente da abordagem de Viktor Frankl. Entretanto, cabe entender a concepção de amor assumida neste estudo. Segundo Fromm (1966), existem dois tipos de amor: o verdadeiro, que é um amor maduro, identificado como uma atitude que se caracteriza pelo cuidado, responsabilidade, respeito e conhecimento do outro, e o falso, que é submisso, passivo e neurótico. Nesse amor falso, o ser em questão é dependente do outro e não mantém sua integridade; isso é claramente o contrário do amor verdadeiro.

Neste ponto, é importante traçar a diferença entre o gostar e o amar. O gostar pode implicar uma relação de afeição e respeito, mas apenas no amar há uma necessidade contínua de cuidar e de estar próximo do outro, compartilhando intimidade e estabelecendo confiança mútua. É igualmente necessário indicar a existência de um amor apaixonado, definido por um desejo forte de união com a outra pessoa, cuja ausência é percebida como um vazio; de modo similar, constata-se também a existência de um amor companheiro, cultivado nas semelhanças e nas diferenças, havendo nele o desejo de se 
revelar um ao outro (Hernández \& Oliveira, 2003).

Nessa caracterização dos tipos de amor, Robert Sternberg (1989) tem dado contribuição importante ao propor sua teoria triangular do amor, que define três tipos: compromisso, intimidade e paixão, cuja medida foi adaptada ao contexto brasileiro (Gouveia, Fonsêca, Cavalcanti, Diniz, \& Dória, 2009; Hernandez \& Oliveira, 2003). Segundo Sternberg (1989), o compromisso evidencia a decisão de amar outra pessoa, mantendo esse amor; a intimidade acentua o desejo de promover o bem-estar da pessoa amada, seu respeito e valorização, o entendimento e o apoio mútuos, e, finalmente, a paixão revela os desejos e a necessidade de autoestima, a entrega, a submissão e a satisfação sexual.

Partindo do modelo de Sternberg (1989), Yela $(1997,2006)$ propôs refinamentos, sugerindo um modelo tetrangular do amor. Concretamente, esse autor manteve as dimensões de compromisso e intimidade, porém subdividiu a de paixão, que passou a ser definida em dois fatores específicos: paixão erótica e paixão romântica. A paixão erótica acentua a dimensão fisiológica do amor, sendo fugaz; a paixão romântica, por outro lado, é mais duradoura, e envolve aspectos e estereotipias de cunho social atribuídos ao comportamento dos enamorados. A intimidade assinala um vínculo especial de união afetiva, com apoio afetivo, compreensão, comunicação, confiança, segurança e conforto, que se fariam mais presentes com a convivência. O compromisso seria o fator que manteria a relação em detrimento dos problemas que pudessem surgir no relacionamento (Yela, 1997).

Em termos evolutivos, de início, teria lugar o enamoramento, que contempla a conquista, e podem ser fundamentais as paixões erótica, principalmente, e romântica; nesse contexto de amor passional, com forte conotação erótica e romântica, costuma ter espaço a intimidade, que, por vezes, vai dar espaço ao compromisso (Yela, 1997). Segundo esse autor, o companheirismo predominaria no decorrer do relacionamento e caracterizaria o amor como mais estável e duradouro, o que tornaria mais plausíveis o compromisso e a intimidade e daria espaço para os componentes de paixão romântica e, sobretudo, erótica. Nesse marco, entende-se que o amor é um elemento primordial para as relações entre casais; embora existam diferentes formas, não são modos estanques de se relacionar, mas de interagir, e formam o amor completo, ideal (Sternberg, 1989). Provavelmente, o amor incondicional, completo, pleno, seja a forma mais saudável e capaz de tornar toda relação mais duradoura e confiável (Franco \& Aragón, 2005), embora essa modalidade possa não ser tão comum na atualidade, principalmente em tempos de ficar.

\section{O fenômeno do ficar}

A revolução sexual, a partir dos anos 60 , provocou mudanças no comportamento sexual das pessoas, redefiniu papéis de gênero e afetou os relacionamentos de intimidade interpessoal. Segundo Rodrigues (1992), a quebra das normas propiciou formas alternativas de relacionamentos. De fato, com a liberdade sexual, as relações sexuais muitas vezes se tornaram um ato mecânico, desvinculadas de afeto e amor, intencionando-se apenas a satisfação física e psíquica momentânea. Esses comportamentos banalizaram a sexualidade e tornaram-na bastante acessível e comum no meio social, o que influenciou diretamente a formação da personalidade das pessoas (May, 1992).

O processo de ressignificação do sexo representa a liberação da sexualidade e de um contexto social que se pauta no individualismo, que busca desenfreadamente a satisfação e a realização pessoal. A partir dos anos 80 , as pessoas começaram a estabelecer relacionamentos afetivos marcados pela falta 
No ficar, não existem delimitações, regras ou limites; se assim forem exigidas, serão negociadas algumas vezes previamente a qualquer relacionamento (Caramaschi, 2007). de compromisso com o outro, que definiu modalidade até então desconhecida: o ficar (Jesus, 2005). Este é um relacionamento superficial, casual e momentâneo que pode durar desde o tempo de um beijo até alguns dias, e é caracterizado principalmente pela falta de compromisso entre os ficantes; esses encontros, muitas vezes, implicam intimidade sexual, mas não proporcionam, necessariamente, intimidade ou vínculo emocional. Mas, segundo Rieth (2002), o ficar não envolve obrigatoriamente relações sexuais; de fato, em pesquisa realizada com estudantes universitários, foi possível observar que as mulheres concebem o ficar apenas como o comportamento de beijar (Pirotta, 2002).

No ficar, não existem delimitações, regras ou limites; se assim forem exigidas, serão negociadas algumas vezes previamente a qualquer relacionamento (Caramaschi, 2007). Nesse sentido, não se configura a obrigação de fidelidade no ficar, que possibilita a flexibilidade de trocas afetivas e a experimentação de maior número de parceiros, pois tudo é permitido, uma vez acordado. Nessa configuração mais recente de relacionamento, percebe-se a mudança da situação histórica da mulher, que passa de submissão à vontade do homem para viver sua própria vontade; evidentemente, isso não significa que a mulher não sofra mais com a exploração do homen, apenas que sua decisão de ficar se apresenta como atitude mais aceita socialmente, que não produz vergonha ou desonra (Justo, 2007).

O ficar pode até ser analisado como um relacionamento romântico, já que nele existe o ato de cortejar, do qual poderia se originar um namoro (Castro, Abramovay, \& Silva, 2004). Esse tipo de relacionamento, embora considerado próprio da juventude, não é exclusivo de adolescentes, já que está presente em outras faixas etárias. Alguns consideram o ficar apenas uma forma de conhecimento, não havendo diferença com paquerar ou flertar, porém, estes têm início com troca de olhares e uma conversa reservada, ocasião em que se procura conhecer a outra pessoa. Por outro lado, o ficar pode envolver diretamente um contato físico mais intenso ou mesmo um envolvimento sexual (Justo, 2007). Esse tipo de relacionamento pode ou não acontecer com a intenção de que surja algo mais sério, e favorece aos seus praticantes a análise de maior número de parceiros do que se estivessem namorando firmemente. Desse modo, o ficar se apresenta como uma forma de explorar, testar e provar o(a) outro(a).

Embora seja possível perceber o ficar sob uma ótica mais negativa, há quem evidencie seu lado positivo. Esse relacionamento, por exemplo, favoreceria o não envolvimento das pessoas em uma relação séria, protegendo-as da iminência do sofrimento que resulta da perda da pessoa amada (Mayor, 2007). Nesse sentido, no contexto da pós-modernidade, o amor romântico está cedendo lugar para o amor confluente (esporádico), em que não é mais o amor eterno que predomina, mas aquele no qual a finitude passa a ser uma possibilidade real, evitando-se a ansiedade desnecessária (Justo, 2007). Porém, isso pode ser diferente para rapazes e moças. Castro et al. (2004) observaram, em seu estudo, que os rapazes ficam pela possibilidade de variar de parceiras, obtendo por isso uma valoração positiva de seus pares. Por outro lado, para as moças, é importante estabelecer limites, pois para elas o grande número de parceiros é valorado negativamente; essa mesma pesquisa indica que as moças gostam de namorar, enquanto os rapazes preferem ficar.

Em resumo, os relacionamentos se apresentam como chave na vida das pessoas, principalmente na de jovens adultos em etapa de constituir família. Embora o amor seja um sentimento ancestral, a existência de relacionamentos casuais, a exemplo dos que se configuram como o ficar, é uma realidade inegável. Compreender esse tipo de relacionamento, suas implicações 
psicológicas, parece fundamental nos dias de hoje. Foi precisamente esse aspecto que motivou o presente estudo. Partindo dos modelos teóricos de Frankl $(1989,1994)$ e Yela $(1997,2006)$, objetivou-se conhecer em que medida os tipos de amor estariam correlacionados com o sentido de vida (vazio existencial).

\section{Método}

\section{Participantes}

Participaram do estudo 199 estudantes de instituições públicas de ensino superior de Campina Grande, PB, com idades entre 16 e 41 anos $(m=21,3 ; d p=3,36)$, quase equitativamente distribuídos quanto ao sexo, com pequeno predomínio do sexo feminino (51\%); majoritariamente, eram solteiros (93,5 \%) e estavam matriculados em cursos de áreas biomédicas (42\%), ciências exatas (46\%) e humanas (12\%).

\section{Instrumentos}

Os participantes receberam um livreto composto por partes principais:

Neste Propósito de Vida (PIL-Test) - esse instrumento avalia o nível de realização de sentido de vida e de vazio existencial, tendo sido proposto Crumbaugh e Maholick (1964), com base na teoria de Viktor Frankl, e revisado por Harlow, Newcomb e Bentler (1987), constituindo a versão PIL-Test- R. Essa última versão foi adaptada para o Brasil por Aquino, Correia, Marques, Sousa, Freitas, Dias e Araújo (2009), e resultou em um conjunto de 12 itens respondidos em escala de sete pontos, variando de 1 (Discordo totalmente) a 7 (Concordo totalmente). Três fatores principais parecem caracterizar essa medida, como seguem: desespero existencial $(\alpha=0,65)$, que constitui a percepção de que a vida é vazia, o que faz com que a pessoa tenha sensação de desespero e prefira nunca ter nascido, se sinta aborrecida e tenha presente a ideação suicida; realização existencial ( $\alpha=0,75)$, cuja percepção da vida é sempre empolgante, constantemente nova, valiosa, é fonte de prazer e satisfação e dotada de objetivos claros, e vazio existencial $(\alpha=$ $0,78)$, pela qual se considera a vida sem sentido, sem metas e sem propósito algum (Aquino et al., 2009).

Escala Tetrangular do Amor - foi elaborada por Yela (2006) com o fim de mensurar o amor a partir de quatro componentes, a saber: intimidade (Recebo considerável apoio emocional de [...]; Entendo-me bem com [...]; compromisso (Espero amar [...] por toda minha vida; Considero firme meu compromisso com [...]); paixão erótica (Sinto que meu corpo reage quando [...] me toca; Fico excitado(a) sexualmente quando beijo [...]); paixão romântica (Minha relação com [...] é muito romântica; Existe algo quase mágico na minha relação com [...]). Cada componente é representado por cinco itens, com uma lacuna para que a pessoa imagine o nome daquela que ama, respondidos em escala de cinco pontos que varia de $\mathbf{1}$ (Não me descreve nada) a $\mathbf{5}$ (Descreve-me totalmente). Um dos objetivos deste estudo é a obtenção dessa estrutura fatorial tetrafatorial.

Questionário demográfico - essa parte procurou reunir informações sobre os participantes do estudo, com a finalidade de caracterizar a amostra: idade, sexo, estado civil, curso e importância da religiosidade na vida da pessoa (escala de resposta variando de $\mathbf{1}=$ Nenhuma importância a $\mathbf{5}$ = Muito importante). Além disso, perguntou-se se a pessoa estava namorando e há quanto tempo, em que medida concordava com o ficar (escala de resposta de $\mathbf{1}$ = Discordo totalmente a $\mathbf{7}=$ Concordo totalmente) e, finalmente, com que frequência costumava ficar (escala de resposta de $\mathbf{1}=$ Nunca a $\mathbf{5}=$ Frequentemente).

\section{Procedimento}

Inicialmente, solicitou-se a autorização para realizar a pesquisa a cada professor responsável 
pela turma. Com sua permissão, procedeuse à coleta dos dados. Cinco estudantes de Psicologia, devidamente treinados, ficaram responsáveis por essa aplicação. Procurouse informar aos estudantes os objetivos da pesquisa, identificada pelo estudo das formas vigentes de relacionamento entre jovens adultos. Indicou-se que sua participação seria voluntária, e foi assegurado o anonimato e destacado que não existiam respostas certas ou erradas. Solicitou-se que cada participante assinasse o Termo de Consentimento Livre e Esclarecido antes de começar a responder os questionários. O tempo demandado para concluir sua participação variou entre 15 e 25 minutos.

\section{Análise de dados}

As análises foram realizadas com o PASW e AMOS. Com o primeiro programa, foram calculadas estatísticas descritivas (frequência, média e desvio-padrão), correlações de Pearson, indicadores de adequação da matriz de correlação para efetuar análise fatorial (KMO e Teste de Esfericidade de Bartlett) e alfa de Cronbach. O segundo programa foi utilizado para realizar a análise fatorial confirmatória com a medida do amor; considerou-se como entrada a matriz de covariâncias, tendo sido adotado o estimador ML (Maximum Likelihood), e estimados múltiplos indicadores de ajuste, com seus respectivos critérios de adequação do modelo teórico (Byrne, 2001; Pilati \& Laros, 2007): 2 $<\chi^{2}$ g.l. (razão qui-quadrado por graus de liberdade) < 3, GFI (Goodness-of-Fit Index), AGFI (Adjusted Goodness-of-Fit Index) e CFI (Comparative Fit Index) =0,90, e RMSEA (RootMean-Square Error of Approximation) $=0,08$.

Três indicadores têm sido comumente considerados para comparar modelos alternativos (Byrne, 2001; Garson, 2003). O Expected Cross-Validation Index (ECVI) e o Consistent Akaike Information Criterion (CAIC) revelam ser mais adequado o modelo que apresenta valores menores. Tais indicadores, contudo, não oferecem uma prova estatística; nesse caso, sugere-se considerar a diferença entre os qui-quadrados $\left(\chi^{2}\right)$ e os respectivos graus de liberdade $\left[\Delta \chi^{2}(\mathrm{gl})\right]$ dos modelos, penalizando aquele com maior $\chi^{2}$.

\section{Resultados}

Os resultados deste estudo são apresentados em duas partes principais: (1) a adequação psicométrica da Escala Tetrangular do Amor e (2) os correlatos do amor, considerando o sentido da vida, as variáveis demográficas (sexo, idade, estado civil e religiosidade) e os indicadores de relações afetivas (se está namorando, se já ficou, em que medida concorda com ficar e razões de ficar).

Evidências de validade fatorial e consistência interna da ETA

Inicialmente, procurou-se considerar a matriz de correlações para checar a adequação de se realizar uma análise fatorial. Nesse caso, consideraram-se os seguintes indicadores: KMO $(0,91)$ e o Teste de Esfericidade de Bartlett $\left[\chi^{2}\right.$ $(190)=2138,1, p<0,001]$, que corroboram essa possibilidade. Portanto, parece pertinente pensar em uma estrutura em que emerge ao menos um fator. Apesar de ser viável realizar uma análise fatorial exploratória com os dados, em razão de evidências teóricas e empíricas sobre essa medida, como descrito previamente, decidiu-se levar a cabo uma análise fatorial confirmatória. Três modelos alternativos foram testados: o primeiro modelo $\left(\mathbf{M}_{\mathbf{1}}\right)$ admitiu uma estrutura unifatorial, com todos os itens saturando no mesmo fator; o segundo modelo $\left(\mathbf{M}_{\mathbf{2}}\right)$, coerente com a proposta de Sternberg (1988), assumiu uma estrutura trifatorial (compromisso, intimidade e paixão), e, finalmente, o terceiro modelo $\left(\mathbf{M}_{3}\right)$ comprovou a hipótese de uma estrutura tetrafatorial, em que a paixão se subvidide em paixão erótica e paixão romântica. Os resultados dessas análises são sumarizados na Tabela 1, a seguir. 
Tabela 1. Comparação dos modelos fatoriais da Escala Tetrangular do Amor

\begin{tabular}{|c|c|c|c|c|c|c|c|}
\hline Modelos & $\chi^{2}$ & g.l. & $\chi^{2 / g . I}$ & CFI & RMSEA (IC90\%) & ECVI & CAIC \\
\hline Quatro fatores & 390,03 & 164 & 2,38 & 0,89 & $0,083(0,073-0,094)$ & 2,43 & 679,52 \\
\hline Três fatores & 540,63 & 167 & 3,24 & 0,76 & $0,106(0,096-0,116)$ & 3,17 & 811,25 \\
\hline Um fator & 749,80 & 170 & 4,41 & 0,72 & $0,131(0,122-0,141)$ & 4,19 & $1.001,54$ \\
\hline
\end{tabular}

Conforme é possível observar nessa tabela, o modelo que admite quatro fatores $\left(\mathbf{M}_{3}\right)$ se mostra o mais promissor. Seus indicadores de ajuste estão próximos do que tem sido admitido na literatura, isto é, $2<\chi^{2} / g . I<3, C F I=0,90$ e RMSEA $=0,08$. Destaca-se que todos os itens apresentaram saturações estatisticamente diferentes de zero no seu fator correspondente $(\chi \neq 0 ; z>3,75, p<$ 0,001 ), com valor médio de 0,61 , portanto, assume-se como adequada a estrutura fatorial observada no presente contexto de pesquisa. Os quatro fatores dessa medida apresentaram os seguintes níveis de consistência interna (alfa de Cronbach padronizado, $\chi)$ : compromisso $(\chi=0,81)$, intimidade $(\chi=0,78)$, paixão erótica $(\chi=0,88)$ e paixão romântica $(\chi=0,80)$.

\section{Correlatos existenciais e demográficos do amor}

Inicialmente, procurou-se correlacionar os fatores do amor com aqueles de sentido da vida. $\mathrm{O}$ compromisso se correlacionou diretamente com a realização existencial $(r=0,37, p<0,001)$; a intimidade o fez com desespero existencial $(r=-0,18, p<0,05)$, realização existencial $(r=0,22$, $p<0,01)$ e vazio existencial $(r=-0,22, p<0,01)$; a paixão romântica se correlacionou com dois fatores de sentido da vida: realização existencial $(r=0,21, p<0,01)$ e vazio existencial $(r=-0,18$, $p<0,05)$, e, finalmente, não se observou qualquer correlação significativa para o fator de amor paixão erótica.

Tiveram-se em conta três variáveis que evidenciam relacionamento e disposição para ficar, correlacionando-as com os fatores do amor. No caso, o tempo de namoro se correlacionou positivamente com paixão erótica ( $r=0,16, p<0,05)$, paixão romântica $(r=0,23, p<0,01)$, intimidade $(r=0,27, p<0,001)$ e, principalmente, compromisso $(r=0,30, p<0,001)$. Por outro lado, no que se refere à frequência com que a pessoa fica, as correlações foram todas negativas, embora significativas para os três seguintes fatores do amor: compromisso $(r=-0,20, p<0,01)$, intimidade $(r=-0,21, p<0,01)$ e romântica $(r=-0,26, p<0,001)$. Padrões similares de correlação foram observados para o grau de concordância que a pessoa expressa em relação a ficar: compromisso $(r=-0,21, p<0,01)$, intimidade $(r=-0,25, p<0,001)$ e paixão romântica $(r=-0,26, p<0,001)$.

Três variáveis pessoais foram correlacionadas com os fatores do amor: sexo $(0=$ feminino, $1=$ masculino), idade e religiosidade (escala de $0=$ Nada religioso a $5=$ Totalmente religioso). Destas, unicamente o sexo se correlacionou com paixão romântica $(r-0,15, p<0,05)$, e a idade o fez com paixão erótica $(r=0,19, p<0,01)$. A média de tempo de namoro apenas para solteiros foi de 14,2 meses ( $d p=22,7)$, variando de 0 (não estava namorando) a 240 meses. Ao investigar a associação entre o tempo da relação interpessoal e o tipo de amor, observaram-se os seguintes coeficientes, segundo o tipo de amor: compromisso $(r=0,30, p<0,001)$, intimidade $(r=0,27, p$ $<0,001)$, paixão romântica ( $r=0,23 ; p<0,01)$ e paixão erótica $(r=0,16, p<0,05)$. Por outro lado, a concordância ou disponibilidade de ficar se mostrou inversamente correlacionada com os tipos de amor, não tendo sido significativo o coeficiente apenas para a paixão erótica $(r=-0,07$, 
$p>0,05)$ : paixão romântica $(r=-0,26, p<$ $0,001)$, intimidade $(r=-0,25, p<0,001) \mathrm{e}$ compromisso $(r=-0,21, p<0,01)$.

\section{Discussão}

Este artigo objetivou conhecer como o amor e o ficar se relacionam entre si e com as dimensões de sentido de vida entre jovens. Entretanto, como requisito para alcançar tal objetivo, pretendeu-se ainda conhecer evidências psicométricas da medida de amor. Estima-se que esses objetivos tenham sido alcançados. Não obstante, reconhecemse as limitações potenciais da pesquisa, sobretudo no que se refere à amostra, que foi de conveniência e específica (estudantes universitários), não permitindo qualquer generalização dos achados. A pesquisa, portanto, é uma explicação plausível acerca de indicadores de como ocorre o fenômeno do amor na atualidade, mas demandaria conhecer outros contextos e personagens. Por exemplo, o que dizer de jovens dos ensinos fundamental e médio? O que poderia estar ocorrendo na terceira idade, quando muitos relacionamentos começam? Certamente, esses estudos complementares contribuiriam para compreender o amor e o ficar em outras fases de desenvolvimento, decidindo se são variáveis características de um grupo específico ou do contexto cultural em que as pessoas estão inseridas. Apesar dessas ponderações, os resultados, no geral, foram na direção teoricamente esperada, o que permite creditar-lhes algum valor científico (ou ao menos heurístico), discutindo-os a seguir.

\section{Adequação psicométrica da Escala Tetrangular do Amor}

Esse instrumento reuniu evidências de validade fatorial e consistência interna, coerentes com os estudos de Yela $(1997,2006)$. Nesse sentido, os indicadores de ajuste resultantes da análise fatorial confirmatória, ao testarem modelos com um, três e quatro fatores, mostraram que este último era mais adequado, atendendo recomendações da literatura (Byrne, 2001; Pilati \& Laros, 2007). Ficaram demonstradas, assim, as evidências de validade fatorial dessa escala. Quanto aos coeficientes de consistência interna (alfas de Cronbach) de seus fatores, todos podem ser considerados satisfatórios, porque estão acima do ponto de corte comumente recomendado $(0,70$; Pasquali, 2003). Desse modo, apresentaramse igualmente evidências favoráveis desse parâmetro psicométrico.

\section{Correlatos dos construtos amor e ficar com o sentido da vida}

Como se observou, o tipo de amor compromisso se correlacionou positivamente com a realização existencial. Pode-se pensar, portanto, que, no compromisso, estão presentes não apenas as características corporal e psíquica do(a) parceiro(a), mas, sobretudo, os elementos que o(a) definem como únicos e irrepetíveis. Provavelmente, no estágio em que o(a) companheiro(a) é percebido(a) como insubstituível, é configurada uma expectativa de amor duradouro, eterno. Frankl (1994) advoga que uma das vias para a realização de sentido é por meio do ato coexistencial, que significa um encontro autêntico com o ser amado, o que pode explicar a correlação entre essas duas variáveis.

No caso da intimidade, esta se associou negativamente com o desespero e o vazio existencial. A expressão do amor como ato coexistencial pode ser percebida por meio da relação interpessoal, que encontra apoio social, visto que, na intimidade, o indivíduo se comunica bem com o(a) parceiro(a), sendo compreendido(a) e entendido(a) por ele(a). Assim, a comunicação entre parceiros pode ser considerada um valor vivencial, pois estaria relacionada com a vivência de um $t u$, que proporciona aos estudantes uma via para superar a sensação de desvalor da vida (Frankl, 1994). 
O fator paixão romântica se associou positivamente com a realização existencial e negativamente com o vazio existencial. Essas correlações pode ser mais bem compreendidas quando Frankl (1994) concebe que a meta primordial da existência é a autotranscendência, isto é, o fato de a pessoa estar voltada para algo ou para alguém além de si mesma, o que pode ser obtido por meio do romantismo, da contemplação. Nesse caso, o indivíduo se esquece de si mesmo e volta-se para o ser amado, o que lhe dá maior sensação de sentido e de valor da vida e, por conseguinte, o previne do vazio existencial.

Por fim, o fator amor erótico não se associou a qualquer fator da medida de sentido de vida, embora Frankl conceba que a busca excessiva pelo prazer pode ser uma das manifestações do vazio existencial. Nesse marco, conjeturase que o prazer possa ser um efeito secundário do encontro existencial, e apenas quando este é intencionado provoca o desprazer. Possivelmente, na fase de desenvolvimento dos participantes do estudo, não se configura exatamente a busca ou a consumação de um encontro existencial, o que explicaria a ausência de relação entre as dimensões analisadas. Além disso, pode-se também pensar que o amor erótico talvez não seja um componente importante para o início do relacionamento afetivo duradouro, não sendo condição suficiente para conferir um sentido à existência humana.

No que diz respeito ao tempo de namoro, este se associou diretamente a paixão erótica (correlação mais fraca), paixão romântica, intimidade e compromisso (correção mais forte). Esses achados corroboram aqueles descritos na pesquisa de Yela (1998). Naquela oportunidade, esse autor observou que, com o passar do tempo no relacionamento, há diminuição das paixões erótica e romântica, e aumentam o compromisso e a intimidade.

O conjunto desses resultados atesta a contribuição da teoria de Frankl (1989), quando este concebe que o amor deve integrar todas as dimensões do ser humano: biopsíquico-noético. Segundo esse autor, o id é integrado na relação eu-tu. Dessa maneira, o erótico pode constituir forma de expressão do amor, sendo plausível pensar que, com o tempo de namoro, a pessoa amada passa a ser percebida como única e irrepetível, o que realimenta o vínculo erótico-sexual. Nesse contexto, o vínculo interpessoal tende a aumentar, posto que há maior apoio afetivo acompanhado de confiança, comunicação e compreensão entre os enamorados. Isso beneficiaria a captação das potencialidades da pessoa amada bem como a intenção de se estabelecer um compromisso duradouro.

O ficar é outra forma de vínculo abordada neste estudo. Talvez não seja propriamente o amor, mas um elemento correlato, que favorece (ou impede) que este surja. Esse tipo de relacionamento é direcionado principalmente para a corporeidade e a busca de sensações momentâneas, tornando compreensível que a frequência do ficar tenha se associado negativamente com o compromisso, a intimidade e o amor romântico. Destaca-se, pois, que, nesse tipo de relacionamento, não existe compromisso ou segurança entre os ficantes, conforme apontou pesquisa de Rieth (2002). De fato, quando se decide manter o relacionamento sério, este já não é mais rotulado de ficar, mas adquire a denominação de namoro. Castro, Abramovay e Silva (2004) afirmam que o ficar pode ser traduzido como o desencanto dos jovens com o casamento. Em termos mais psicológicos, Justo o concebe como apenas um dentre outros fenômenos de subjetivação produzidos na sociedade contemporânea, marcado pelo caráter efêmero, provisório e abreviado dos vínculos.

\section{Considerações finais}

Os achados desta pesquisa favorecem melhor entendimento da dimensão amor nos tempos 
atuais, contrastando-o ou comparando-o com uma atitude recorrente denominada ficar. Nesse contexto, constatou-se que o amor possui a função de realizar existencialmente o ser humano ao servir como fator de proteção contra o desespero e o vazio existencial, corroborando as evidências clínicas e os ensaios filosóficos de Frankl (1989). Ademais, aponta um conceito fundamental dessa teoria, isto é, a autotranscendência, como um fenômeno de realização humana; quando o ser humano está inclinado para algo ou para alguém que não ele mesmo, configura-se um motivo legítimo para a sua própria realização.

Finalmente, como ressaltou Lukas, "quando nunca se chega a uma realização profunda entre duas pessoas, está faltando na vida do homem uma grande área de realização" (1992, p. 125). É provável que muitos jovens não queiram assumir ainda responsabilidades, preterindo os relacionamentos com vínculos mais prolongados e, em consequência, aderindo àqueles de curta duração, caracterizados como o ficar. Este proporcionaria ao ser humano apenas o gozo de sensações momentâneas, enquanto a intimidade, o compromisso e a paixão (erótica e, sobretudo, romântica) resultariam na realização existencial. Estudos futuros deveriam ser realizados sobre o amor e o ficar, considerando, por exemplo, elementos explicativos que tenham como fundamento princípios orientadores, a exemplo de crenças e de práticas religiosas, de desenvolvimento moral e, principalmente, de valores humanos.

Thiago Antônio Avellar de Aquino,

Doutor em Psicologia Social pela Universidade Federal da Paraíba, Professor do Departamento de Ciências das

Religiões da Universidade Federal da Paraíba, PB - Brasil.

E-mail: logosvitae@ig.com.br

Valdiney Veloso Gouveia

Doutor Pela Universidade Complutense de Madri, Professor Titular de Psicologia social do Departamento de

Psicologia da Universidade Federal da Paraíba, PB - Brasil; Bolsista de Produtividade 1A.

E-mail:vvgouveia@gmail.com

Karizy Soany Costa Patrício

Graduada em Psicologia pela Universidade Estadual da Paraíba, Psicóloga Clínica, PB - Brasil.

E-mail: karizysoany@hotmail.com

\section{Maria Gorete Sarmento da Silva}

Graduada em Psicologia pela Universidade Estadual da Paraíba, Mestranda em Psicologia pela Universidade

Federal do Rio Grande do Norte, RN - Brasil.

E-mail: goretesarmento@yahoo.com.br

Jacqueline Lisete de Macedo Bezerra

Graduada em Psicologia pela Universidade Estadual da Paraíba, Psicóloga Clínica, PB - Brasil.

E-mail: jaclisete@hotmail.com

Valdemir Bezerra de Souza Júnior

Graduado em Psicologia pela Universidade Federal da Paraíba, Psicólogo clínico, PB - Brasil.

E-mail: valdemirpsi@yahoo.com

\section{Waldemar Moreira de Oliveira Neto}

Graduado em Psicologia pela Universidade Estadual da Paraíba, Psicólogo Clínico, PB - Brasil.

E-mail: waldemar_neto@hotmail.com

Endereço para envio de correspondência:

Rua Mário Batista Júnior, n. 75, apt. 302, Miramar

João Pessoa - PB - Brasil. CEP 58043-130

Recebido 3/12/2010, Aprovado 15/10/2011. 


\section{Referências}

Adler, A. (1998). What Life Should Mean to You. Minnesota: Hazelden (Trabalho original publicado em 1931)

Aquino, T. A. A., Correia, A. P. M., Marques, A. L. C., Sousa, C. G. Freitas, H. C. de A., Araújo, I. F., Dias, P. dos S., \& Araújo, W. F. (2009). Atitude religiosa e sentido da vida: um estudo correlacional. Psicologia: Ciência e Profissão, 29, 228-243.

Byrne, B. M. (2001). Structural equation modeling with AMOS: Basic concepts, applications, and programming. Mahwah, NJ: Lawrence Erlbaum Associates.

Caramaschi, S. (2007). Ficar ou namorar: intimidade sexual e intimidade emocional em conflito. Recuperado em 07 de março, 2007, de www.faac.unesp.br/pesquisa/nos/ novos_textos/b/ficar.htm.

Castro, M. G., Abramovay, M., \& Silva, L. B. (2004). Juventude e sexualidade. Brasília, DF: Unesco Brasil.

Crumbaugh, J. H., \& Maholick, L. T. (1964). The psychometric approach to Frankl's concept of noogenic neurosis. Journal of Clinical Psychology, 20, 200-207.

Fizzotti, E. (1998). Abraham Maslow e Viktor Frankl. Os ritos de cura como auto-realização e como busca de sentido. In F. Dalpino (Org.), Liturgia e terapia: a sacramentalidade a serviço do homem na sua totalidade (pp. 235-275). São Paulo: Paulinas.

Franco, B. E. R., \& Aragón, R. S. (2005). Construcción y validación de una escala para medir adicción al amor en adolescentes. Enseñanza e Investigación en Psicología, 10, 127-141.

Frankl, V. E. (1989). Psicoterapia e sentido da vida. São Paulo: Quadrantes.

Frankl, V. E. (1994). Em busca de sentido: um psicólogo no campo de concentração. Petrópolis, RJ: Vozes / Sinodal.

Freud, S. (1974) O mal-estar na civilização. In S. Freud, Edição standard brasileira das obras psicológicas completas de Sigmund Freud (J. Salomão, trad., Vol. 21, pp. 81-171). Rio de Janeiro: Imago. (Trabalho original publicado em 1929)

Fromm, E. (1966). A arte de amar. Belo Horizonte, MG: Itatiaia

Garson, G. D. (2003). PA 765 Statnotes: An online textbook Recuperado em 17 de maio de 2005 de http://www2.chass. ncsu.edu/garson/pa765/statnote.htm.

Gouveia, V.V., Fonsêca, P. N., Cavalcanti, J. P. N., Diniz, P. K. C., \& Dória, L. C. (2009). Versão abreviada da Escala Triangular do Amor: evidências de validade fatorial e consistência interna. Estudos de Psicologia, 14, 31-39.

Harlow, L. L., Newcomb, M. D., \& Bentler, P. M. (1987). Purpose in life test assessment using latent variable methods. British Journal of Clinical Psychology, 26, 235-236.

Hernandez, J. A. E., \& Oliveira, I. M. B. (2003). Os componentes do amor e a satisfação. Psicologia: Ciência e Profissão, 23, 58-69.

Jesus, J. S. O. (2005). Ficar ou namorar: um dilema juvenil. PSIC. Revista Psicológica da Vetor Editora, 6, 67-73.

Justo, J. S. (2007). O ficar na adolescência e paradigma de relacionamentos amorosos da contemporaneidade. Recuperado em 07 de março de 2007, de http://www.scielo. br/pdf/rdpsi/v17n1/v17n1a05.pdf.

Lukas, E. (1989). Logoterapia: a força desafiadora do espírito. Santos, SP: Edições Loyola.
Lukas, E. (1992). Prevenção psicológica. Petrópolis, RJ / São Leopoldo, RS: Vozes.

May, R. (1992). Amor e vontade: eros e repressão (Á. B. Weissenberg, trad.). Petrópolis, RJ: Vozes.

Mayor, S. S. (2007). A consagração do "ficar". Recuperado em 06 de março de 2007, de www.riototal.com.br/feliz-idade/ psicologia09.htm.

Pasquali, L. (2003). Psicometria: teoria dos testes na psicologia e na educação. Petrópolis, RJ: Vozes.

Pilati, R., \& Laros, J. A. (2007). Modelos de equações estruturais em psicologia: conceitos e aplicações. Psicologia: Teoria e Pesquisa, 23, 205-216.

Pirotta, K. C. M. (2002). Juventude e saúde reprodutiva: valores e condutas relacionadas com a contracepção entre universitários. Trabalho apresentado no XIII Encontro da Associação Brasileira de Estudos Populacionais, Ouro Preto, MG.

Platão. (1991). Diálogos. São Paulo: Nova Cultural. (Coleção Os pensadores).

Rieth, F. (2002). A iniciação sexual na juventude de mulheres e homens. Horizontes Antropológicos, 8, 77-93.

Rodrigues, A. (1992). Psicologia social para principiantes: estudos da interação humana. Petrópolis, RJ: Vozes.

Sternberg, R. J. (1989). El triangulo del amor: intimidad, pasión y compromiso. Barcelona: Paidós.

Weingärtner, C. L., John, D., Bonamigo, L. R., \& Goidanich, M. (1995). O ficar e o namoro visto pelos adolescentes. Psicologia: Reflexão e Crítica, 8, 181-203.

Yela, C. (1997). Curso temporal de los componentes básicos del amor a lo largo de la relación de pareja. Psicothema, 2, 1-15.

Yela, C. (2006). The evaluation of love simplified version of the Scales for Yela's Tetrangular model basead on Sternberg's model. European Journal of Psychological Assessment, 22, 21-27. 